\title{
Infestação natural de fêmeas bovinas de corte por ectoparasitas na Região Sudeste do Brasil $^{1}$
}

\section{Ana Mary da Silva2, Maurício Mello de Alencar ${ }^{3,4}$, Luciana Correia de Almeida Regitano ${ }^{3,4}$, Márcia Cristina de Sena Oliveira ${ }^{3}$}

\author{
1 Pesquisa financiada pelo CNPq. \\ 2 Doutoranda em Genética e Evolução, na UFSCar, Bolsista do CNPq. \\ ${ }^{3}$ Embrapa Pecuária Sudeste, São Carlos, SP, Brasil, Caixa Postal 339, CEP: 13560-970. \\ ${ }^{4}$ Bolsista do CNPq.
}

RESUMO - Avaliou-se o grau de infestação natural por ectoparasitas em fêmeas bovinas de corte de três grupos genéticos. Foram realizadas contagens, de julho de 2003 a dezembro de 2004, de carrapatos (Rhipicephalus (Boophilus) microplus), moscas-dos-chifres (Haematobia irritans) e bernes (larvas de Dermatobia hominis) em fêmeas dos grupos genéticos Nelore $(\mathrm{NE})$, Angus $\times$ Nelore $(\mathrm{AN})$, Canchim $\times$ Nelore $(\mathrm{CN})$ e Simental $\times$ Nelore $(\mathrm{SN})$ infestadas naturalmente. Foram feitas de 6 a 10 contagens em cada animal, totalizando 5.384 observações em fêmeas de sete estádios fisiológicos (bezerras, novilhas vazias, novilhas prenhes, vacas primíparas, com ou sem bezerro, e vacas pluríparas, com ou sem bezerro). Os dados, transformados por $\log _{10}(\mathrm{n}+1)$, foram analisados pelo método dos quadrados mínimos, com um modelo estatístico que incluiu os efeitos de grupo genético da fêmea, de animal dentro de grupo genético (erro a), de ano-época da contagem, de estádio fisiológico e da interação grupo genético $\times$ ano-época da contagem. A diferença entre os grupos genéticos dependeu do ano-época da contagem, contudo, em geral, as fêmeas nelores foram as menos infestadas pelo carrapato e as Angus $\times$ Nelore, as mais infestadas pela mosca-dos-chifres e pelo berne. Houve efeito de estádio fisiológico da fêmea em todas as três características estudadas, e as diferenças variaram com a característica. Apesar da interação grupo genéitco $\times$ ano-época de contagem, existem diferenças entre os grupos genéticos Nelore, Canchim $\times$ Nelore, Angus $\times$ Nelore e Simental $\times$ Nelore quanto ao grau de infestação natural por carrapatos, por moscas-dos-chifres e por bernes.

Palavras-chave: Bos taurus $\times$ Bos indicus, Dermatobia hominis, Haematobia irritans, Nelore, Rhipicephalus (Boophilus) microplus

\section{Natural infestation by external parasites in beef cattle females in southern Brazil}

ABSTRACT - It was evaluated in this work, the degree of natural infestation by external parasites in beef cattle females from three genetic groups. Countings of cattle tick (Rhipicephalus (Boophilus) microplus), horn fly (Haematobia irritans) and beef-worm (Dermatobia hominis) were performed from July 2003 to December 2004 in females from the genetic groups Nellore (NE), Angus $\times$ Nellore $(A N)$, Canchim $\times$ Nellore $(C N)$, and Simmental $\times$ Nellore $(S N)$ naturally infested. It was realized from 6 to 10 countings in each animal, totalizing 5,384 observations in females at seven physiological stages (calf; empty heifers, pregnant heifers, primiparous cows with or without calf; and pluriparous cows, with or without calf). Data, which were transformed by $\log _{10}(n+1)$, were analyzed by the least square method with a statistical model that included effects of the female genetic group, of the animal within a genetic group (error a), year-season counting, physiological state, and year-season $\times$ genetic group interaction. Differences among genetic groups depended on year-season counting; however, in general, Nellore females were the least infected by ticks, and Angus $\times$ Nellore females were the most infected by horn flies and by beef-worms. There was a physiological stage effect of the female in all the three studied characteristics and the differences changed accordingly to the trait. Despite of the counting year-season $\times$ genetic group, there are differences among Nellore, Canchim $\times$ Nelore, Angus $\times$ Nellore and Simmental $\times$ Nelore genetic groups regarded to the degree of natural infestation by cattle tick, horn fly and beef-worm.

Key Words: Bos taurus $\times$ Bos indicus, Dermatobia hominis, Haematobia irritans, Nellore, Rhipicephalus (Boophilus) microplus 


\section{Introdução}

Os ectoparasitas podem causar prejuízos à bovinocultura de corte, pois ocasionam perda de peso, danificam o couro, transmitem agentes patógenos e/ou produzem lesões que predispõem os animais a infecções secundárias (Honer \& Gomes, 1992). Entre os ectoparasitas, o carrapato Rhipicephalus (Boophilus) microplus, a moscados-chifres (Haematobia irritans) e o berne (Dermatobia hominis) são os mais importantes para a pecuária do Brasil.

Para controlar essas parasitoses, métodos químicos, biológicos e de manejo têm sido utilizados (Pruett, 1999; Andrade, 2001; Fraga et al., 2003). Entretanto, estudos têm mostrado que há diferenças entre grupos genéticos quanto à resistência a ectoparasitas. Em bovinos, vários autores observaram aumento do grau de infestação por carrapatos com o aumento da proporção de Bos taurus nos animais Europeu $\times$ Zebu (Lemos et al., 1985; Moraes et al., 1986; Oliveira \& Alencar, 1987; Oliveira et al., 1989; Oliveira \& Alencar, 1990; Guaragna et al., 1992; Wambura et al., 1998). Quanto à mosca-dos-chifres, Tugwell et al. (1969) observaram que animais da raça Brahman apresentaram maior potencial de repelência ao parasita do que animais das raças Aberdeen Angus e Charolesa, e que a intensidade de infestação foi associada à porcentagem de genótipo Brahman. Moraes et al. (1986) verificaram que a intensidade parasitária do berne foi maior em animais taurinos do que em zebuínos; Oliveira \& Alencar (1990) observaram maior intensidade parasitária quanto maior a proporção de holandês em animais cruzados holandês × guzerá, e Gomes et al. (1996) verificaram que animais Nelore apresentaram menor infestação, seguidos dos F1 europeu $\times$ Nelore e por último dos Ibagé (5/8 Aberdeen Angus + 3/8 Zebu), que apresentaram a maior infestação.

A existência de diferenças entre grupos genéticos quanto ao grau de infestação por ectoparasitas sugere a possibilidade de se utilizar o cruzamento entre raças para capitalizar as vantagens da heterose e da complementaridade em características produtivas e de adaptação, visando ao aumento da eficiência produtiva dos rebanhos do País. Entretanto, a escolha das raças a serem utilizadas depende de caracterização criteriosa do esquema de cruzamento; portanto, neste trabalho, o objetivo foi avaliar o grau de infestação natural de fêmeas bovinas de corte de diferentes grupos genéticos ao carrapato, à mosca-dos-chifres e ao berne.

\section{Material e Métodos}

Os dados deste experimento foram provenientes de bovinos do rebanho pertencente à Embrapa Pecuária
Sudeste, localizada no município de São Carlos, SP. O clima local é tropical de altitude, que, segundo a classificação de Köeppen, é o Cwa, quente com inverno seco. Nos últimos 13 anos, até o final do período de coleta de dados deste trabalho, junho e julho foram os meses mais frios $\left(18,3^{\circ} \mathrm{C}\right)$; fevereiro foi o mês mais quente $\left(23,6^{\circ} \mathrm{C}\right)$; agosto, o mês mais seco (20 mm); e janeiro, o mês mais chuvoso (256 mm).

Foram feitas de 6 a 10 contagens dos ectoparasitas de julho de 2003 a dezembro de 2004, em fêmeas dos grupos genéticos Nelore (NE, $n=184)$, Canchim $\times$ Nelore $(C N, n=153)$, Angus $\times$ Nelore $(A N, n=123)$ e Simental $\times$ Nelore $(S N$, $\mathrm{n}=120$ ), infestadas naturalmente, totalizando 5.384 observações. Todos os animais de todos os grupos genéticos possuíam a mesma base genética de Nelore, ou seja, são procedentes de vacas da raça Nelore ou aneloradas de mesma origem e permaneceram com suas mães até a desmama em pastagens de capim-tanzânia (Panicum maximum) e de capim-marandu (Brachiaria brizantha). As fêmeas eram filhas de 21 touros da raça Nelore e de 22 touros da raça Canchim, por meio de monta natural, e de 23 touros da raça Aberdeen Angus e de 25 touros da raça Simental, por meio de inseminação artificial. Esses animais, pertencentes a diferentes estádios fisiológicos (bezerra, novilha prenha, novilha vazia, vaca primípara, com ou sem bezerro, e vaca plurípara, com ou sem bezerro), foram mantidos, durante o período de coleta de dados, em lotes de manejo em pastagens de Brachiaria decumbens e Panicum maximum. Todos os animais foram submetidos ao manejo sanitário padrão da fazenda, incluindo vacinações contra a febre aftosa, brucelose e clostridioses e testes para tuberculose e brucelose. Durante o experimento, não foi feito o controle químico de ectoparasitas. Os lotes de manejo foram formados com animais de mesmo estádio fisiológico e dos quatro grupos genéticos.

Para o cálculo da infestação por carrapatos, foram contadas todas as teleóginas presentes em um lado do corpo do animal, com tamanho $\geq 4,5 \mathrm{~mm}$ de comprimento. No caso das moscas-dos-chifres, foram contadas todas aquelas localizadas no dorso e no lombo dos animais, e para os bernes, todos os nódulos localizados em toda a extensão do corpo do animal. Para efetuar essas avaliações, os animais foram imobilizados em tronco de contenção.

Os dados, transformados por $\log _{10}(n+1)$, foram analisados pelo método dos quadrados mínimos, cujos modelos estatísticos incluíram os efeitos de grupo genético (GG) da fêmea, de animal dentro de GG (erro a), de anoépoca da contagem (AE), de estádio fisiológico e da interação “GG × AE”, além do resíduo (erro b).

Na formação dos grupos de contemporâneos, no que se refere ao efeito de ano-época de contagem (AE), o ano foi 
dividido em quatro épocas, quais sejam: época 1 (verão janeiro a março), época 2 (outono - abril a junho), época 3 (inverno julho a setembro) e época 4 (primavera - outubro a dezembro).

\section{Resultados e Discussão}

Todos os efeitos incluídos no modelo estatístico influenciaram significativamente $(\mathrm{P}<0,01)$ todas as características estudadas.

As diferenças entre os grupos genéticos foram dependentes de ano-época (Tabela 1, Figura 1). No caso do carrapato, a interação foi significativa, já que os animais do grupo Simental $\times$ Nelore foram semelhantes aos Angus $\times$ Nelore no inverno e na primavera de 2003 e no verão e outono de 2004, porém apresentaram maior infestação do que os Angus $\times$ Nelore nos outros anos-épocas do experimento. Os animais do grupo Nelore foram menos infestados do que os cruzados em todos os anos-épocas, com exceção dos Canchim × Nelore na primavera de 2003.

No caso da mosca-dos-chifres, a infestação dos animais Nelore foi menor do que a dos animais Canchim $\times$ Nelore na primavera de 2003 e no outono e no inverno de 2004, mas foi semelhante nos outros ano-época. Na primavera de 2004, os animais Nelore apresentaram infestação por mosca-dos-chifres semelhante à dos Simental $\times$ Nelore Também no verão e na primavera de 2004, os animais Simental $\times$ Nelore tiveram infestação de moscas semelhante à dos animais Canchim $\times$ Nelore.
Quanto ao berne, a interação foi significativa já que os animais Simental $\times$ Nelore foram mais infestados do que os Nelore e os Canchim $\times$ Nelore, apenas no inverno de 2003 e na primavera de 2004, apresentando infestação semelhante nos outros ano-época.

Quando se desconsiderou a interação grupo genético $\times$ ano-época, observou-se (Tabela 1) que as maiores infestações de carrapato ocorreram no inverno de 2003 e no outono de 2004, enquanto as menores ocorreram na primavera de 2003 e no verão de 2004. Os trabalhos realizados no Brasil quanto aos efeitos da época do ano sobre o grau de infestação por carrapatos apresentam resultados muito variados. Guaragna et al. (1988), em bovinos de leite da raça Mantiqueira no Vale do Paraíba, estado de São Paulo, e Oliveira et al. (1989), em bovinos da raça Canchim criados em pastagens em São Carlos, região central do estado de São Paulo, verificaram maior infestação no outono e no inverno. Veríssimo et al. (1997), trabalhando com bovinos mestiços de leite, criados em Colina, região norte do estado de São Paulo, e Andrade et al. (1998), em bovinos da raça Gir, criados em Uberaba, no Triângulo Mineiro, observaram maior infestação no outono. Fraga et al. (2003), em bovinos da raça Caracu criados em pastagens em Paranaíba, sudeste do estado de Mato Grosso do Sul e em Sertãozinho, norte do estado de São Paulo, relataram que o pico de infestação ocorreu no verão, com queda pronunciada na primavera.

A maior infestação por moscas ocorreu na primavera de 2004, seguida do outono de 2004, enquanto a menor infestação ocorreu no inverno de 2003, seguida do inverno

Tabela 1 - Número (média do número transformado) de carrapatos, moscas-dos-chifres e bernes em bovinos de três grupos genéticos

\begin{tabular}{|c|c|c|c|c|c|c|c|}
\hline \multirow[b]{2}{*}{ Item } & \multicolumn{6}{|c|}{ Ano-época } & \multirow[b]{2}{*}{ Média } \\
\hline & $\begin{array}{l}2003 / 3 \\
\text { Inverno }\end{array}$ & $\begin{array}{c}2003 / 4 \\
\text { Primavera }\end{array}$ & $\begin{array}{c}\text { 2004/1 } \\
\text { Verão }\end{array}$ & $\begin{array}{l}2004 / 2 \\
\text { Outono }\end{array}$ & $\begin{array}{l}\text { 2004/3 } \\
\text { Inverno }\end{array}$ & $\begin{array}{c}2004 / 4 \\
\text { Primavera }\end{array}$ & \\
\hline Grupo genético & \multicolumn{6}{|c|}{ Carrapato } & \\
\hline Nelore & $1,33 \mathrm{C}$ & $0,40 \mathrm{~B}$ & $0,43 \mathrm{C}$ & $0,54 \mathrm{C}$ & $0,56 \mathrm{C}$ & $0,67 \mathrm{C}$ & $0,65 \mathrm{D}$ \\
\hline Canchim $\times$ Nelore & $1,87 \mathrm{~B}$ & $0,59 B$ & $0,76 \mathrm{~A}$ & $1,20 \mathrm{~B}$ & $0,81 \mathrm{~B}$ & $1,06 \mathrm{~B}$ & $1,05 \mathrm{C}$ \\
\hline Angus $\times$ Nelore & $2,37 \mathrm{~A}$ & $0,71 \mathrm{~A}$ & $0,66 \mathrm{~A}$ & $1,91 \mathrm{~A}$ & $0,93 \mathrm{~B}$ & $0,98 B$ & $1,26 \mathrm{~B}$ \\
\hline Simental $\times$ Nelore & $2,53 \mathrm{~A}$ & $0,96 \mathrm{~A}$ & $0,80 \mathrm{~A}$ & $1,85 \mathrm{~A}$ & $1,12 \mathrm{~A}$ & $1,33 \mathrm{~A}$ & $1,43 \mathrm{~A}$ \\
\hline \multirow[t]{2}{*}{ Média } & $2,02 \mathrm{a}$ & $0,67 \mathrm{e}$ & $0,66 \mathrm{e}$ & $1,37 b$ & $0,85 d$ & $1,01 \mathrm{c}$ & 1,09 \\
\hline & \multicolumn{6}{|c|}{ Mosca-dos-chifres } & \\
\hline Nelore & $1,24 B$ & $2,96 \mathrm{~B}$ & $3,21 \mathrm{C}$ & $3,36 \mathrm{D}$ & $2,59 \mathrm{D}$ & 3,93B & $2,89 \mathrm{C}$ \\
\hline Canchim $\times$ Nelore & $1,25 B$ & $3,47 \mathrm{~A}$ & $3,31 \mathrm{BC}$ & $3,60 \mathrm{C}$ & $2,81 \mathrm{C}$ & 3,93В & $3,06 \mathrm{C}$ \\
\hline Angus $\times$ Nelore & $2,42 \mathrm{~A}$ & $3,86 \mathrm{~A}$ & 3,92A & $4,15 \mathrm{~A}$ & $3,60 \mathrm{~A}$ & $4,41 \mathrm{~A}$ & $3,73 \mathrm{~A}$ \\
\hline Simental $\times$ Nelore & $2,20 \mathrm{~A}$ & $3,65 \mathrm{~A}$ & $3,47 \mathrm{~B}$ & $3,91 \mathrm{~B}$ & $3,22 B$ & $4,08 \mathrm{~B}$ & $3,42 B$ \\
\hline \multirow[t]{2}{*}{ Média } & $1,78 \mathrm{e}$ & $3,49 c$ & $3,48 c$ & $3,75 b$ & $3,06 \mathrm{~d}$ & $4,09 a$ & 3,27 \\
\hline & \multicolumn{5}{|c|}{ Berne } & & \\
\hline Nelore & $0,34 \mathrm{C}$ & $0,05 \mathrm{C}$ & $0,11 \mathrm{~B}$ & $0,26 \mathrm{~B}$ & $0,31 \mathrm{~B}$ & $0,23 \mathrm{D}$ & $0,22 \mathrm{C}$ \\
\hline Canchim $\times$ Nelore & $0,27 \mathrm{C}$ & $0,08 \mathrm{BC}$ & $0,07 \mathrm{~B}$ & $0,17 \mathrm{~B}$ & $0,37 \mathrm{~B}$ & $0,37 \mathrm{C}$ & $0,22 \mathrm{C}$ \\
\hline Angus $\times$ Nelore & $2,20 \mathrm{~A}$ & $1,09 \mathrm{~A}$ & $0,86 \mathrm{~A}$ & $1,28 \mathrm{~A}$ & $2,00 \mathrm{~A}$ & $1,96 \mathrm{~A}$ & $1,56 \mathrm{~A}$ \\
\hline Simental $\times$ Nelore & $0,58 \mathrm{~B}$ & $0,27 \mathrm{~B}$ & $0,13 \mathrm{~B}$ & $0,21 \mathrm{~B}$ & $0,45 B$ & $0,66 \mathrm{~B}$ & $0,38 \mathrm{~B}$ \\
\hline
\end{tabular}

Médias com letras maiúsculas diferentes na coluna indicam diferença $(\mathrm{P}<0,05)$ entre grupos genéticos pelo teste $\mathrm{t}$.

Médias com letras minúsculas diferentes nas linhas indicam diferença entre ano-época pelo teste $\mathrm{t}(\mathrm{P}<0.05)$. 

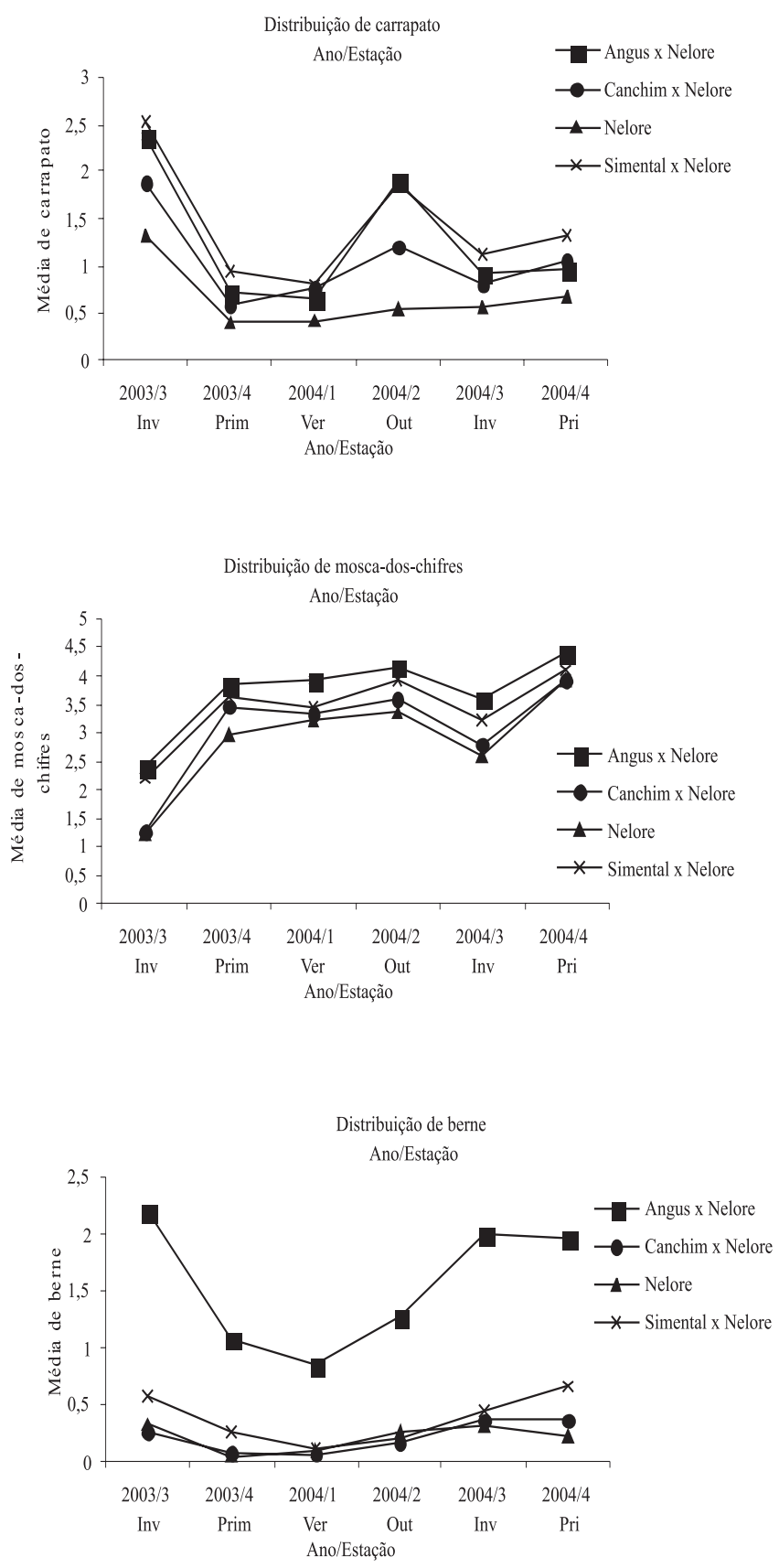

Figura 1 - Médias do número de carrapatos, moscas-dos-chifres e bernes em bovinos de três grupos genéticos.

de 2004. Esses resultados concordam com aqueles obtidos por Fraga et al. (2005), que verificaram menor infestação no inverno e maior na primavera, em bovinos Caracu criados em pastagens em Paranaíba, MS e Sertãozinho, São Paulo.

A menor infestação por bernes ocorreu no verão de 2004, enquanto as maiores infestações ocorreram no inverno de 2003 e no inverno e na primavera de 2004. Esses resultados concordam apenas em parte com aqueles obtidos por Oliveira \& Alencar (1990), que verificaram maior infestação no início do período chuvoso (primavera), em comparação com o período de verão, em bovinos cruzados holandêsguzerá, criados em São Carlos, São Paulo.

Certamente, diferenças de clima ocorridas nos locais e períodos de observação dos vários estudos citados são responsáveis pelas diferentes infestações dos parasitas nas diferentes épocas do ano. Neste trabalho, as maiores infestações de carrapato ocorreram em épocas (inverno de 2003 e outono de 2004) em que as médias mensais de temperatura variaram de 18,1 a $22,0^{\circ} \mathrm{C}$ e as de umidade relativa de 57 a $79 \%$, enquanto as menores infestações ocorreram em épocas (primavera e verão de 2003) em que as médias mensais de temperatura estiveram entre 22,5 e $23,7^{\circ} \mathrm{C}$ e as de umidade relativa entre 72 e $85 \%$. A mais baixa infestação de moscas-dos-chifres ocorreu no inverno de 2003, época em que houve baixas médias mensais de temperatura $\left(18,4\right.$ a $\left.19,2^{\circ} \mathrm{C}\right)$ e de umidade relativa $(57 \%$ a 64\%), seguida do inverno de 2004, época em que as médias mensais de umidade relativa (51 a $80 \%$ ) e de temperatura $\left(18,3\right.$ a $\left.23,7^{\circ} \mathrm{C}\right)$ variaram muito, mas que foram, em média, baixa e mediana, respectivamente. Com relação ao berne, houve tendência de menores infestações nas épocas (primavera e verão de 2003) em que houve maiores médias mensais de temperatura $\left(22,5\right.$ a $\left.23,7^{\circ} \mathrm{C}\right)$ e de umidade relativa (72 a 85\%).

Quanto aos efeitos de grupo genético, nos ano-época de maior infestação de carrapatos, houve tendência de as diferenças entre os grupos genéticos se destacarem; os animais com maior proporção de zebu (NE e depois $\mathrm{CN}$ ) foram menos infestados em relação àqueles com maior proporção de raças de origem europeia (AN e SN; Figura 1 e Tabela 1). Os resultados mostram que, mesmo as fêmeas cruzadas Canchim $\times$ Nelore que têm, em média, apenas 31,25\% de europeu, apresentaram, em geral, maior infestação de carrapatos do que o Nelore. Quando se desconsiderou a interação grupo genético $\times$ ano-época, a tendência foi a mesma, ou seja, os animais Nelore apresentaram menor infestação, seguidos dos Canchim $\times$ Nelore e, por último, dos Angus $\times$ Nelore e dos Simental $\times$ Nelore. Isso concorda com vários autores (Lemos et al., 1985; Moraes et al., 1986; Oliveira \& Alencar, 1987; Oliveira et al., 1989; Oliveira \& Alencar, 1990; Teodoro et al., 1994; Wambura et al., 1998; Santos Jr. et al., 2000; Silva et al., 2007), que, trabalhando com animais de várias composições genéticas, também verificaram maior infestação natural ou artificial em animais com maior proporção de Bos taurus.

O fato de o gado zebu conviver com o carrapato desde os primórdios em seu processo evolutivo, enquanto o gado europeu estabeleceu contato com esse parasita, apenas no momento de sua introdução nos trópicos, é um dos fatores que explicam a superioridade de animais zebuínos quanto 
à resistência ao carrapato (Andrade, 2001). Apesar de os mecanismos de resistência ao carrapato serem pouco conhecidos, acredita-se que o processo de irritabilidade causado pela inoculação de substâncias estranhas junto com a saliva pela larva conduz o animal à prática de autolimpeza, ou seja, lambedura, roçadura ou ato de se coçar, tentando livrar-se das larvas (Kemp et al., 1976; Koudstaal et al., 1978). Riek (1962) e Willadsen et al. (1978) observaram reações de hipersensibilidade em bovinos resistentes ao parasita, que podem causar a queda dos carrapatos. Outros mecanismos como anastomoses arteriovenosas na pele dos animais (Schleger et al., 1981) e quantidade de mastócitos dérmicos (Moraes et al., 1992) também podem estar relacionados à resistência ao carrapato.

No caso da mosca-dos-chifres e do berne, apesar de haver interação grupo genético $\times$ ano-época, a tendência foi de os animais Nelore, Canchim $\times$ Nelore e Simental $\times$ Nelore apresentarem menor infestação do que os animais Angus $\times$ Nelore em todas as épocas, com destaque para a infestação por bernes. Também, desconsiderando-se a interação, os animais Nelore e Canchim $\times$ Nelore apresentaram, em geral, menor infestação por mosca-doschifres e por bernes do que os animais com maior proporção de Bos taurus (SN e AN). Entre os 1/2 europeu + 1/2 zebu, os cruzados com raça de origem britânica (AN) foram mais infestados do que os cruzados com raça de origem continental (SN). Tugwell et al. (1969) observaram maior intensidade de infestação por moscas-dos-chifres em animais puros das raças Aberdeen Angus e Charolesa do que em animais Brahman. Moraes et al. (1986), comparando as infestações por bernes em rebanhos de Bos taurus e de Bos indicus, verificaram que a intensidade parasitária foi maior no taurino. Oliveira \& Alencar (1990), avaliando animais de seis "graus de sangue" holandês-guzerá, verificaram maior infestação por bernes nos animais de elevada proporção de "sangue" holandês. Gomes et al. (1996), em bovinos de corte criados em Campo Grande, MS, observaram maior infestação por bernes em animais com maior proporção de Bos taurus, ou seja, animais da raça Ibagé (5/8 europeu) apresentaram maior infestação, seguidos de animais $1 \frac{1}{2}$ europeu $+1 / 2$ zebu e, por último, animais zebu.

Quanto ao estádio fisiológico, a infestação por carrapatos apresentou a seguinte ordem crescente: bezerras, novilhas vazias, novilhas prenhes, vacas primíparas, vacas pluríparas sem bezerro e vacas pluríparas com bezerro (Tabela 2). Os resultados da literatura científica com relação ao estádio fisiológico dos animais e a infestação por carrapatos são também variados. Neste trabalho, o efeito de estádio fisiológico está confundido com o efeito de idade dos animais. Teodoro et al. (1994), em bovinos de leite, não observaram efeito de estádio fisiológico, mas verificaram efeito quadrático da idade, indicando que os animais mais jovens e os animais mais velhos foram mais resistentes. Andrade et al. (1998), em bovinos da raça Gir, verificaram que os animais mais velhos são os mais susceptíveis ao carrapato. Fraga et al. (2003), em bovinos da raça Caracu, também observaram efeito quadrático da idade do animal sobre a infestação por carrapatos; a infestação foi máxima aos 5,18 anos de idade.

Neste trabalho, o número de moscas-dos-chifres foi menor nas vacas pluríparas com bezerro e nas vacas primíparas sem bezerro e maior nas novilhas prenhes e nas vacas primíparas com bezerro; os outros grupos de animais apresentaram infestação intermediária (Tabela 2). Fraga et al. (2005), em fêmeas da raça Caracu, verificaram efeito quadrático de idade do animal sobre o número de moscasdos-chifres; a menor infestação ocorreu nos animais de 3,27 anos de idade.

A infestação por bernes foi maior nas novilhas vazias e menor nas novilhas prenhes e nas vacas primíparas com bezerro (Tabela 2).

Os efeitos de estádio fisiológico verificados neste trabalho podem também incluir efeitos de pastagem e de dia da observação, uma vez que as contagens foram, em geral, realizadas por grupo de manejo, que compreendia animais de estádios fisiológicos semelhantes.

Tabela 2 - Estimativas das médias do número de carrapatos, moscas-dos-chifres e bernes em bovinos de corte de diversos estádios fisiológicos

\begin{tabular}{|c|c|c|c|c|}
\hline Estádio fisiológico & Número & Carrapato & Mosca-dos-chifres & Berne \\
\hline Bezerra & 392 & $0,15 \mathrm{E}$ & $3,26 \mathrm{AB}$ & $0,66 \mathrm{ABC}$ \\
\hline Novilha prenhe & 292 & $0,82 \mathrm{C}$ & $3,42 \mathrm{~A}$ & $0,46 \mathrm{BC}$ \\
\hline Novilha vazia & 1.395 & $0,53 \mathrm{D}$ & $3,41 \mathrm{AB}$ & $0,76 \mathrm{~A}$ \\
\hline Vaca primípara sem bezerro & 977 & $1,40 \mathrm{~B}$ & $3,14 \mathrm{~B}$ & $0,58 \mathrm{ABC}$ \\
\hline Vaca primípara com bezerro & 593 & $1,29 B$ & $3,42 \mathrm{~A}$ & $0,49 \mathrm{C}$ \\
\hline Vaca plurípara sem bezerro & 938 & $1,49 B$ & $3,16 \mathrm{AB}$ & $0,59 \mathrm{ABC}$ \\
\hline Vaca plurípara com bezerro & 797 & $1,99 \mathrm{~A}$ & $3,08 \mathrm{~B}$ & $0,64 \mathrm{AB}$ \\
\hline
\end{tabular}

Médias com letras maiúsculas diferentes na coluna indicam diferença significativa $(\mathrm{P}<0,05)$ entre grupos genéticos pelo teste $t$. 


\section{Conclusões}

O grau de infestação natural por carrapatos, moscasdos-chifres e bernes varia entre os grupos genéticos Nelore, Canchim $\times$ Nelore, Angus $\times$ Nelore e Simental $\times$ Nelore e as diferenças dependem do ano-época. Entretanto, em geral, os animais Nelore são menos infestados por carrapato que os Canchim $\times$ Nelore, que, por sua vez, são menos infestados que os Angus $\times$ Nelore e Simental $\times$ Nelore. Os animais Nelore e Canchim $\times$ Nelore são menos infestados por moscados-chifres e por bernes que os Simental $\times$ Nelore e estes menos que os Angus $\times$ Nelore, portanto, as estratégias de combate a esses parasitas nos animais desses grupos genéticos devem ser diferenciadas.

\section{Referências}

ANDRADE, A.B.F. Análise genética da infestação de fêmeas da raça Caracu por carrapato (Boophilus microplus) e mosca-dos-chifres (Haematobia irritans). 2001. 104f. Tese (Doutorado em Zootecnia) - Faculdade de Ciências Agrárias e Veterinárias, UNESP, Jaboticabal.

ANDRADE, A.B.F.; SILVA, R.G.; COSTA, A.J. et al. Genetic and environmental aspects of the resistance of Zebu cattle to the tick Boophilus microplus. In: WORLD CONGRESS ON GENETICS APPLIED TO LIVESTOCK PRODUCTION, 6., 1998, Armidale: NSW, Austrália. Proceedings... Armidale, 1998. v.27, p.339-342.

FRAGA, A.B.; ALENCAR, M.M.; FIGUEIREDO, L.A. et al. Análise de fatores genéticos e ambientais que afetam a infestação de fêmeas bovinas da raça Caracu por carrapatos (Boophilus microplus), Revista Brasileira de Zootecnia, v.32, n.6, p.1578-1586, 2003 (supl.1).

FRAGA, A.B.; ALENCAR, M.M.; FIGUEIREDO, L.A. et al. Genetics analysis of the infestation of females of Caracu cattle breed by Horn Fly (Haematobia irritans) (L) (diptera, Muscidae). Genetics and Molecular Biology, v.28, n.2, p.242-247, 2005.

GOMES, A.; HONER, M.R.; SILVA, R.L. Intensidade parasitária de larvas de Dermatobia hominis (Linnaeus, jr. 1781) (Diptera: Cuterebridae) em bovinos de diferentes raças criadas extensivamente na região de cerrado em Mato Grosso. Revista Brasileira de Parasitologia Veterinária, v.5, n.2, p.103-106, 1996.

GUARAGNA, G.P.; CARVALHO, J.B.P.; FIGUEIREDO, A.L. et al. Efeito de fatores genéticos e ambientais na infestação natural de carrapato (Boophilus microplus, CANESTRINI) em bovinos leiteiros. Boletim de Indústria Animal, v.45, n.1, p.19-32, 1988.

GUARAGNA, G.P.; CARVALHO, J.B.P.; GAMBINI, L.B. et al. Resistência comparativa de tourinhos das raças Holandesa e Mantiqueira à infestação artificial de carrapato (Boophilus microplus, CANESTRINI). Boletim de Indústria Animal, v.49, n.2, p.73-82, 1992.

HONER, M.R.; GOMES, A. O manejo integrado de mosca dos chifres, berne e carrapato em gado de corte. Campo Grande: EMBRAPA-CNPGC, 1992. 60p. (Circular Técnica, 22).

KEMP, D.H.; KOUDSTAAL, D.; ROBERTS, J.A. et al. Boophilus microplus: The effect of host resistance on larval attachments and growth. Parasitology, v.73, p.123-136, 1976.

KOUDASTAAL, D.; KEMP, D.H.; KERR, J.D. Boophilus microplus: rejection of larvae from British breed cattle. Parasitology, v.73, p.123-136, 1978.
LEMOS, A.M.; TEODORO, R.L.; OLIVEIRA, G.P. et al. Comparative performance of six Holstein-Friesian x Guzera grades in Brazil. 3. Burdens of Boophilus microplus under field conditions. Comparative performance of six HolsteinFriesian x Guzerá grades in Brasil. Animal Production, v.41, p.187-191, 1985.

MORAES, F.R.; COSTA, A.J.; WOELZ, C.R. et al. Ecologia de carrapatos. XV: Susceptibilidade natural comparativa entre taurinos e zebuínos a Boophilus microplus (Canestrini) (Acari, Ixodidae). Arquivo Veterinária, v.2, n.1, p.45-52, 1986.

MORAES, F.R.; MORAES, J.R.E.; COSTA A.J. et al. A comparative study of lesions caused by different parasitic stages of Boophilus microplus (Canestrini) in the skins of naturally infested taurine and zebuine hosts. The correlation of ticks resistance with mast cell counts in the host's skin. Brazilian Journal of Veterinary and Animal Sciences, v.29, p.378383, 1992.

OLIVEIRA, G.P.; ALENCAR, M.M. Resistência de bovinos ao carrapato Boophilus microplus. I. Infestação artificial. Pesquisa Agropecuária Brasileira, v.22, n.4, p.433-438, 1987.

OLIVEIRA, G.P.; ALENCAR, M.M. Resistência de bovinos de seis graus de sangue Holandês-Guzerá ao carrapato (Boophilus microplus) e ao berne (Dermatobia hominis). Arquivo Brasileiro de Medicina Veterinária e Zootecnia, v.42, n.2, p.127-135, 1990.

OLIVEIRA, G.P.; ALENCAR, M.M.; FREITAS, A.R. Resistência de bovinos ao carrapato Boophilus microplus. II. Infestação natural. Pesquisa agropecuária Brasileira, v.24, n.10, p.1267-1271, 1989.

PRUETT, J.H. Immunological control of arthropods ectoparasites - a review. International Journal Parasitology, v,29, p.25-32, 1999.

RIEK, R. F. Studies on the reaction of animals to infestation with tick. VI Resistance of cattle to infestation with the tick Boophilus microplus (Canestrini). Australian Journal of Agricultural Research, v.13, p.532-549, 1962.

SANTOS JR., J.C.B.; FURLONG, J.; DAEMON, E. Controle do carrapato Boophilus microplus (Acari: Ixodidae) em sistemas de produção de leite da microrregião fisiográfica fluminense do grande rio. Ciência Rural, v.30, n.2, p.305-311, 2000.

SCHLEGER, A.V.; LINCOLN, D.R.; BOURNE, A.S. Arteriovenous anatomosis in the dermal vasculature of the skin of Bos taurus cattle, and their relationship with resistance to the tick Boophilus microplus. Australian Journal of Biological Science, v.34, p.26-35, 1981.

SILVA, A.M.; ALENCAR, M.M.; REGITANO, L.A.C. et al. Artificial infestation of Boophilus microplus in beef cattle heifers of four genetic groups. Genetics and Molecular Biology, v.30, n.4, p.1150-1155, 2007.

TEODORO, R.L.; LEMOS, A.M.; MADALENA, F.E. et al. Carga Parasitária de Boophilus microplus em vacas mestiças europeu x zebu. Revista Brasileira de Zootecnia, v.23, n.2, p.223-228, 1994.

TUGWELL, P.; BURNS, E.C.; TURNER, J.W. et al. Brahman breeding as a factor affecting the attractiveness or repellency of cattle to the horn fly. Journal of Economic Entomology, v.62, n.1, p.56-57,1969.

VERÍSSIMO, C.J.; SILVA, R.G.; OLIVEIRA, A.A.D. et al. Resistência e susceptibilidade de bovinos leiteiros mestiços ao carrapato Boophilus microplus. Boletim de Indústria Animal, v.54, n.2, p.1-10, 1997.

WAMBURA, P.N.; GWAKISA, P.S.; SILAYO, R.S. et al. Breedassociated resistance to tick infestation in Bos indicus and their crosses with Bos taurus. Veterinary Parasitology, v.77, p.63-70, 1998.

WILLADSEN, P.; WILLIANS, P.G.; ROBERTS, J.A. et al. Response of cattle to allergens from Boophilus microplus. Institute Journal Parasitology, v.8, p.89-95, 1978. 